\title{
Trilha dos sentidos: entrelaçando os caminhos da ciência e da arte
}

\section{Track of the senses intertwining paths of science and art}

\author{
${ }^{1}$ Manoela Atalah Pinto dos Santos manuatalah@hotmail.com \\ ${ }^{2}$ Sandro Tiago da Silva Figueira \\ ${ }^{3}$ Gláucia Alegre dos Santos Buarque Gusmão
}

\section{RESUMO}

Há um movimento mundial por uma Educação Ambiental mais estimuladora, propiciando o aumento de conhecimentos, mudanças de valores e o aperfeiçoamento de habilidades. O presente trabalho teve como objetivo analisar a realização da "Trilha dos Sentidos" (MATAREZI, 2006), com o intuito de promover nos participantes a conscientização de suas atitudes, posturas e seus quereres, bem como avaliar o desenvolvimento da atividade como um instrumento capaz de desenvolver habilidades na formação do ser humano criativo. Para tal, aplicamos a "Trilha dos Sentidos" durante a disciplina de Ciência e Arte, com os alunos do Programa de Pós-Graduação em Ensino em Biociências e Saúde (EBS/IOC/FIOCRUZ) e através de relatos avaliamos o potencial da atividade. Os resultados indicam que os participantes puderam experimentar o entrelaçamento da sensibilização e conscientização, além de despertar importantes habilidades para seu o desenvolvimento. Ademais, acreditamos que a atividade pode fomentar o diálogo entre as áreas de Ciências e Artes.

Palavras-chave: Ciência e Arte, Educação Ambiental, criatividade, Trilha dos sentidos

\begin{abstract}
There is a global movement for a more stimulating Environmental Education, providing increased knowledge, changes in values and the improvement of skills. This work aimed to make "The Trail of the Senses ", in order to promote the participants awareness of their attitudes, postures and their wants, and to evaluate the activity as a tool to develop skills in the formation of human creative . To this end, we apply "The Trail of the Senses" (MATAREZI, 2006) during the course of Science and Art, with students of Post -Graduate Education in Biosciences and Health (EBS / IOC / FIOCRUZ) and evaluated through reports the potential of the activity. The results indicate that the participants could experience the intertwining of awareness and consciousness, as well as sparking important skills to develop. Furthermore, we believe that the activity can foster dialogue between the areas of Arts and Sciences, two major areas of knowledge.
\end{abstract}

Keywords: Art and Science, Environmental Education, creativity, Track of the senses.

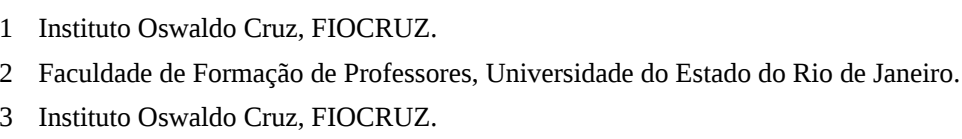




\section{INTRODUÇÃO}

Debruçamo-nos neste texto com o intuito de problematizar os resultados de uma estratégia pedagógica denominada “Trilha dos sentidos” desenvolvida durante disciplina Ciência e Arte I do Programa de Pós-Graduação em Ensino em Biociências e Saúde (EBS/IOC/FIOCRUZ).

Em nosso contexto atual, percebemos o chamamento das diversas esferas governamentais e não governamentais para a necessidade de preservação do meio ambiente. Logo, buscar outras maneiras para sensibilizar as pessoas quanto à relação do seu fazer diário junto à natureza torna-se uma questão sine qua non. "Nunca o homem esteve exposto a mudanças tão rápidas, tão radicais e tão profundas como na contemporaneidade" (SANTOS, 1999, p. 143). E todo esse conjunto resulta em uma mistura complexa e caótica em que nos vemos mergulhados e que têm nos exigido uma série de reflexões sobre o que tem sido e o que queremos de nossas vidas (BONOTO, 2008).

Nesta perspectiva, a Educação Ambiental, conjugada no entrelaçamento entre Ciência e Arte, pode tornarse uma forma satisfatória de mudança de práticas, pois podemos ir além da resolução de conflitos ambientais, englobando sobretudo a transformação da sociedade através de dimensões que superem nossas limitadas formas de expressão e linguagem. Como relata Carvalho(2000), vemos que apesar da identificação das situações de degradação ambiental não ser considerada um exercício muito difícil, devido a certo "consenso" quanto ao seu reconhecimento, o mesmo não se dá quando se busca as propostas para enfrentá-las.

Nosso objetivo com a atividade era promover nos participantes a conscientização de suas atitudes e posturas, clarificando o destaque efetuado por Matarezi, (2006), sobre o necessário afastamento e desligamento progressivo das fontes de sustentação da vida, como também das relações de cuidado, de reciprocidade e solidariedade, que num período anterior também fizeram parte das relações dentro das células familiar e social. Além disso, acreditamos que a atividade pode ser um instrumento capaz de desenvolver habilidades essenciais na formação do ser humano criativo e fomentar o diálogo entre as áreas de Ciências e Artes.

Neste trabalho apresentamos a proposta desenvolvida durante a disciplina, a "Trilha dos sentidos" e analisamos as impressões dos alunos sobre a atividade em que participaram.

\section{1 Pressupostos teóricos:}

Há um movimento mundial por uma Educação Ambiental que seja mais dinâmica, propiciando o aumento de conhecimentos, mudanças de valores e o aperfeiçoamento de habilidades, que são condições básicas para que o ser humano assuma atitudes e comportamentos que estejam em harmonia com o meio ambiente (PADUA; TABANEZ, 1997). Alguns autores ressaltam a importância da reflexão sobre as relações dos seres entre si, do ser humano com ele mesmo e do ser humano com seus semelhantes (MATAREZI, 2006; LOUREIRO, 2005).

Dentro desse contexto, as escolas destacam se como espaços privilegiados na implementação de atividades que propiciem a valorização das diversidades culturais e ambientais, pois este espaço possui como características: a promoção da intensa troca de ideias, discussões e desenvolvimento em favor da cidadania (MACHADO et al., 2007; MACIEL et al., 2010). Segundo Mello (2006), um método importante na Educação Ambiental é transformar a teoria da sala de aula em prática, usando os recursos ecológicos, podendo-se trabalhar as relações “Eu - Meio Ambiente”, “Eu - O Outro” e "Eu - Comigo Mesmo” de forma vivencial.

Reforçando a importância da Educação Ambiental, encontramos nos Parâmetros Curriculares Nacionais (BRASIL, 1997), a preocupação com um ensino que englobe a vida do aluno, o seu meio e sua comunidade a partir da inserção do Meio Ambiente e Saúde como Temas Transversais. Tal inclusão justifica-se pela constatação de que à medida que a humanidade aumenta sua capacidade de intervir na natureza para satisfação das ne- 
cessidades e desejos surgem também tensões e conflitos. Logo, torna-se imprescindível um trabalho pedagógico vinculado "aos princípios da dignidade do ser humano, da participação, da corresponsabilidade, da solidariedade e da equidade” (BRASIL, 1997) conscientizando os alunos dos seus deveres com o meio ambiente.

Em seus estudos e pesquisas, Matarezi (2006) nos convoca a pensar a Educação Ambiental na perspectiva crítica, transformadora e emancipatória, com o intuito de promovermos ações que nos levem a romper com o consumismo desenfreado e a perda de sentido de nossas sociedades assentadas em um desenvolvimento não sustentável. A educação ambiental sustenta uma recente discussão sobre as questões ambientais e transformações de conhecimentos, valores e atitudes que devem ser seguidos diante da nova realidade a ser construída, constituindo uma importante dimensão que necessita ser incluída no processo educacional.

A educação ambiental é recente e está em constante crescimento, desenvolvendo-se com as práticas cotidianas dos educadores. Ela tem a importante função de atingir toda a população, inclusive as novas gerações, formando cidadãos que possam responder pelo processo de mudanças do atual estado ambiental da Terra. Como a educação tradicional não prepara os indivíduos para a complexa realidade global, a educação ambiental tornase uma necessidade, um processo contínuo e permanente que deve abranger todos os níveis escolares e etapas da educação formal e informal (GUIMARÃES, 2007).

A educação ambiental é um processo de educação que segue uma nova filosofia de vida, uma nova cultura comportamental que busca um compromisso do homem com o presente e o futuro do meio ambiente. A sua aplicação torna o processo educativo mais orientado para a formação da cidadania. A educação para o desenvolvimento sustentável, como também pode ser chamada, deve considerar as realidades regionais e respeitar as diversidades culturais das populações. Ela deve se constituir basicamente num ensino interdisciplinar, que deve, com o tempo, evoluir para a transdisciplinaridade de todas as matérias do conhecimento, possibilitando com isso um processo de aprendizagem formador de cidadãos capacitados a viver sustentavelmente (AB'SABER, 1994). Nessa perspectiva, entendemos que a estratégia pedagógica “Trilha dos Sentidos" pode promover em nossos alunos a construção de posturas críticas, que os levem a transformarem/reverem seus hábitos clarificando suas responsabilidades e os emancipando.

Assumindo a complexidade que a temática ambiental põe à educação e conscientes da limitação das nossas formas de expressão, seja a linguagem oral ou escrita, no que tange a conscientização/sensibilização, acreditamos que a proposta da trilha na perspectiva de Matarezi (2006) pode potencializar o processo de ensino-aprendizagem descortinando compreensões, aprendizagens, conhecimentos e descobertas por meio de uma experiência individual e coletiva. Sendo assim os alunos poderão encontrar os sentidos e as conexões ocultas que os integram ao lugar onde vivem. As trajetórias pessoais e coletivas. Os sonhos compartilhados e as utopias concretizáveis (MATAREZI, 2006).

Na tentativa de abarcar a complexidade e os diversos sentidos possíveis da "Trilha dos Sentidos", destacamos o seu potencial como um recurso capaz de produzir reflexões provenientes da Educação Ambiental, assim como de outras áreas de ensino. Dentro dessa esfera, buscamos ressaltar a importância do diálogo entre a Educação Ambiental e outras áreas do conhecimento como as Artes e a Ciência.

Partilhamos da ideia de que a crise no ensino é acompanhada de uma crise de criatividade (FIGUEIRA-OLIVEIRA et al., 2009), pois os indivíduos parecem experimentar as consequências de uma "educação bancária” tão criticada por Freire (1996), acrescida de massiva memorização de conteúdos impostos e apartados de seus contextos e suas questões práticas (CARVALHO e GONÇALVES, 2000; CARVALHO, 2007). As novas correntes educacionais, no entanto, reforçam a interação entre saberes, através de propostas interdisciplinares que instiguem a curiosidade e a capacidade crítica do educando (VERGNANO, 2006). 
Diante do exposto, optamos pela utilização de recursos imaginativos da Arte, nas tarefas ligadas à esfera da Educação Ambiental, estimulando a criatividade nas analogias. O filósofo Renato Janine Ribeiro (2001) defende a necessidade do poliglotismo cultural, da multidisciplinaridade. Ademais, como revela Root-Bernstein (2001) para compreendermos nós mesmos, outras pessoas ou um aspecto da natureza, é imperativo aprendermos a usar as emoções, os sentimentos, as sensações e intuições, sendo essas as bases da imaginação criadora. É necessário introduzir e desenvolver na educação o estudo das características cerebrais, mentais, culturais, dos conhecimentos humanos, de seus processos e modalidades, das disposições tanto psíquicas quanto culturais que o conduzem ao erro ou a ilusão (MORIN, 1997).

\section{2}

\section{TRAJETÓRIA METODOLÓGICA: DEFININDO CAMINHOS A TRILHAR}

\section{1 A proposta: "Trilha dos Sentidos"}

A “Trilha dos Sentidos” trabalha com o imaginário dos participantes. É uma vivência em grupo na qual as pessoas experimentam diferentes situações de olhos vendados e descalças, exercendo intensamente o tato, olfato, paladar e audição (MATAREZI, 2001). Para tal, é montado um ambiente simulador de floresta, em forma de trilha. Neste espaço são distribuídos diferentes recursos naturais. O cheiro dos recursos naturais aguça, inclusive, o olfato dos participantes, contribuindo com a sua percepção sobre a natureza.

A trilha foi realizada no interior de uma sala de aula (Figura 1), na qual dispusemos objetos de diversas texturas, formas e elementos naturais como folhas secas, pequenos galhos e plantas, além de um computador reproduzindo sons da natureza e ventilador para simular o vento do ambiente.

Figura 1 - Visão geral da “Trilha dos sentidos”, na sala de aula.

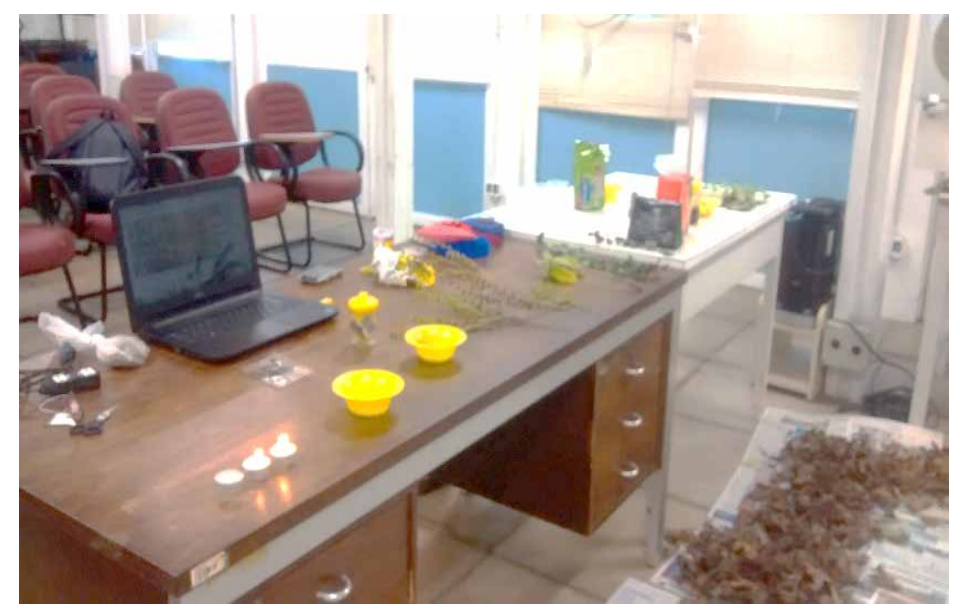

Fonte: Elaboração própria dos autores.

Escolhemos os materiais pautados nas indicações de Matarezi (2006), pois ansiávamos sobretudo, com uma reaproximação dos participantes com o meio ambiente nos seus aspectos naturais, sociais, culturais e históricos, estimulando uma reflexão crítica das inter-relações históricas entre a sociedade, o indivíduo e o lugar onde se vive.

No chão foram colocados jornais amassados e folhas secas e os alunos tiveram que percorrer o caminho passando por esses elementos (Figura 2.). 
Figura 2 - Vista dos materiais colocados na parte inferior da "Trilha dos Sentidos"

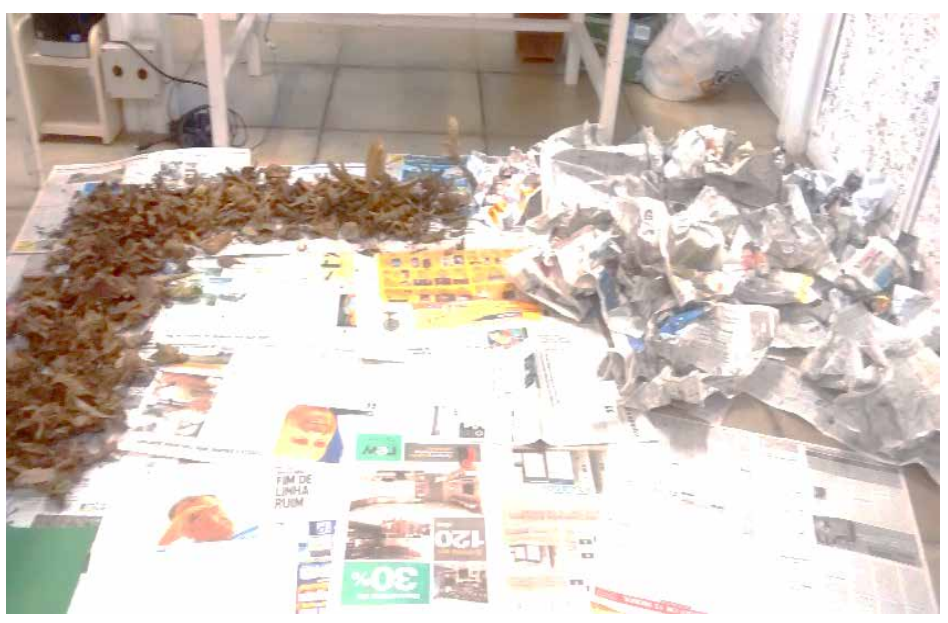

Fonte: Elaboração própria dos autores.

Nas bancadas os materiais foram disponibilizados de acordo com os sentidos a serem estimulados. A primeira parte apresentava plantas com diferentes texturas, umas mais ásperas, outras com aspectos aveludados. Na segunda etapa os alunos foram convidados a tentar identificar os elementos de acordo com seu aroma, como hortelã, cheiro verde, cravo, entre outros. Já na terceira etapa, com autorização dos participantes, eles tentaram identificar um alimento apenas pelo paladar (Figura 3).

Figura 3 - Vista dos materiais dispostos na parte superior da "Trilha dos Sentidos"

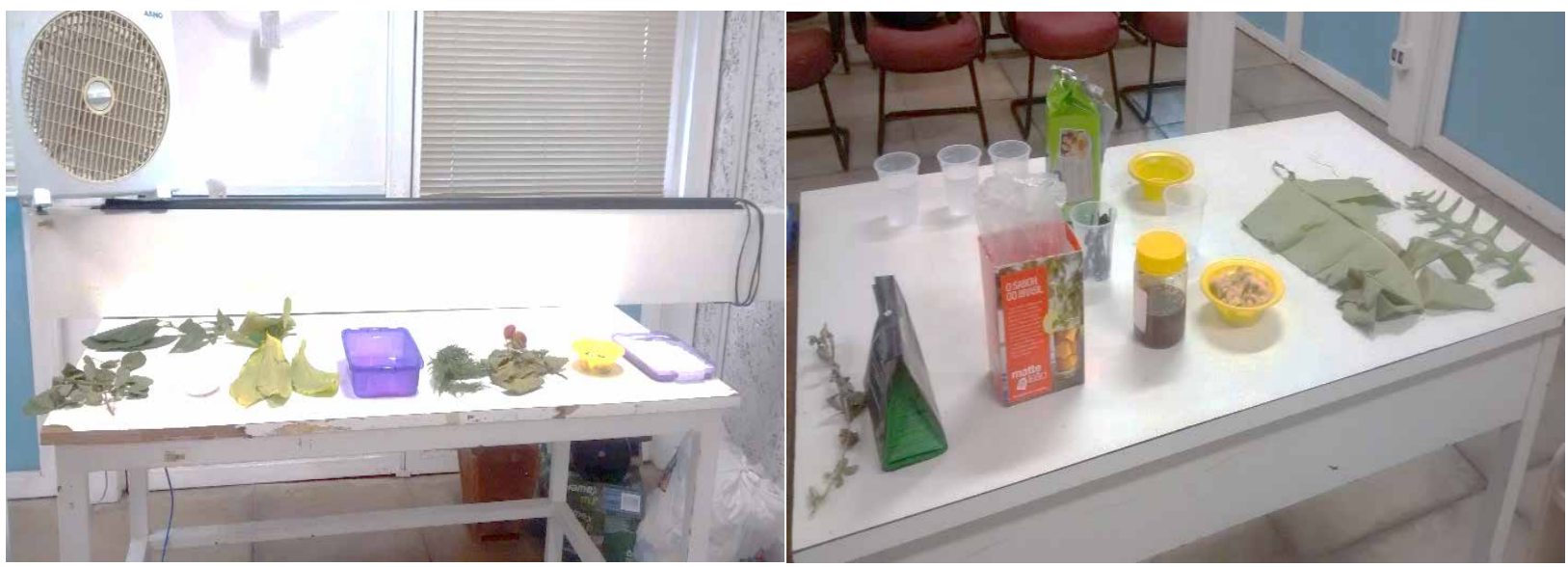

Fonte: Elaboração própria dos autores.

A estratégia de eliminar temporariamente a visão dos participantes (utilizando uma venda) foi a forma encontrada para colocar o sujeito e o coletivo em situação de estranhamento, de desconhecimento e de despertar os demais sentidos que estão via de regra adormecidos, anestesiados. Ao vendar os olhos também criávamos uma atmosfera de confiança e disponibilidade, convidando os participantes a explorarem seus sentidos e ficarem confortáveis com a situação. Ao finalizarem a passagem na trilha, os participantes elaboraram narrativas escritas sobre as sensações experimentadas e reflexões despertadas. Nosso intuito era o de identificar as oportunidades de aprendizagens efetuadas por meio do corpo, dos sentidos e da percepção que articulasse o si mesmo, os outros e a natureza.

Ao final da trilha, a venda foi retirada e os participantes visualizaram uma das partes mais importantes da experiência - a própria imagem - e se deparavam com nossos questionamentos para reflexão a partir de indaga- 
ções como: “Quem sou eu? Quem somos nós? Onde e como vivemos?” (Figura 4). Além disso, a representação do espelho tinha o intuito fazer com que os participantes repensassem questões internas e externas que passam despercebidas no contexto atual em que vivemos.

\section{Figura 4 - Espelho com questionamentos para reflexão dos participantes}

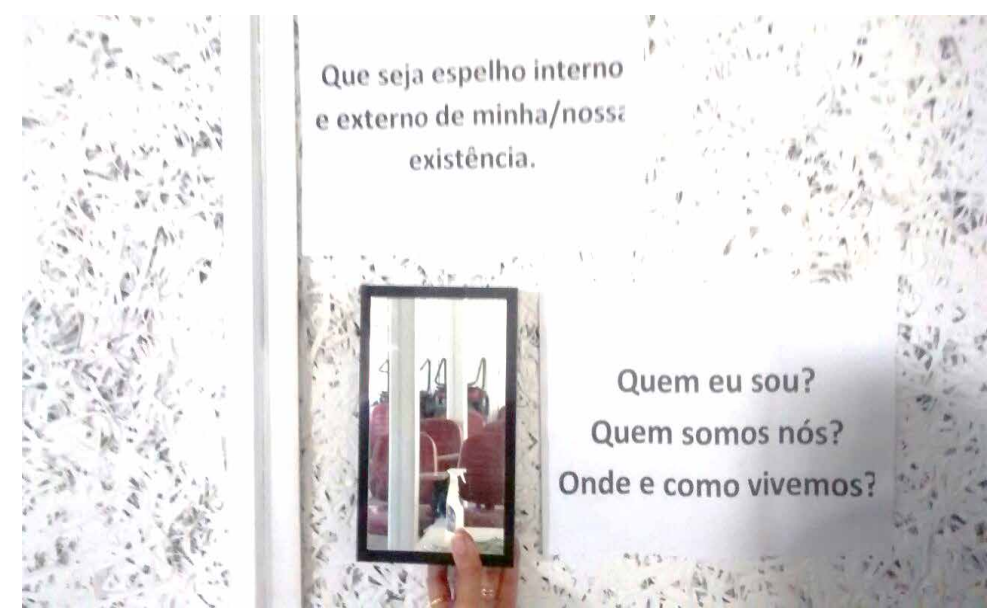

Fonte: Elaboração própria dos autores.

Com o objetivo de clarificar as descobertas narrativas dos participantes, solicitamos que ao final da trilha efetuassem um esforço reflexivo relatando a vivência na "Trilha dos Sentidos" de forma escrita, assim como respondessem a um questionário que contava com indagações sobre o interesse na atividade e sua aplicabilidade na educação básica. Com as narrativas escritas, objetivamos evidenciar a percepção ambiental relacionada a seus modos de ser e estar. Além disso, buscamos observar características que são evocadas pelas Artes como: repensar o pensamento, educar a imaginação, abstrair e evocar imagens (ROOT-BERNSTEIN, 2001).

Entendemos que ao narrar de forma escrita, efetuamos articulações das nossas experiências com as simbolizações num movimento dialógico que congrega as subjetividades, comportamentos, posturas, atitudes e formas de ver e sentir, "as quais são perspectivadas a partir daquilo que cada um viveu e vive” (SOUZA, 2008), comungando, dessa forma, com a perspectiva teórico prática da “Trilha dos Sentidos”.

Dessa forma, podemos conceber as narrativas como um elo que liga as aprendizagens com a dimensão pessoal e interior dos sujeitos, produzindo um conhecimento de si e um conhecimento do fazer pautado numa reflexão crítica.

\section{2 Participantes}

Participaram da pesquisa 10 alunos do Programa de Pós-Graduação em Ensino em Biociências e Saúde (EBS/IOC/FIOCRUZ). Os participantes foram selecionados por estarem cursando a disciplina Ciência e Arte I e serem professores da educação básica.

\section{3 Análise dos dados}

Inscrevemo-nos no âmbito qualitativo de pesquisar (LUDKE; ANDRÉ, 1986) e a abordagem metodológica de nossa trilha dos sentidos baseou-se em Matarezi (2006) que a concebe enquanto um experimento educacional transdisciplinar integrando os objetivos educativos, conservacionistas e terapêuticos. Para o autor, a experimentação baseia-se em atividades de interpretação ambiental, com enfoque socioambiental, que possibilita vivências geradoras de descobertas e narrativas em grupo. 
Elegemos para análise das narrativas escritas o processo de tematização elaborado por Fontoura (2011). Tal perspectiva pauta-se numa reflexividade criteriosa dos depoimentos, na qual o pesquisador torna-se co-construtor dos sentidos do caminhar da pesquisa. A opção por esse eixo de análise justifica-se principalmente por permitir aos envolvidos numa determinada pesquisa, tanto pesquisador quanto os demais sujeitos, explorarem suas visões e práticas profissionais focalizando “uma forma pedagógica de pensar” que conjuga reflexão e aprendizagem concomitantemente.

\section{VIVENCIANDO A “TRILHA DOS SENTIDOS”: DA EMPIRIA À CONCEITUAÇÃO}

Reconhecendo a “Trilha dos Sentidos” enquanto uma forma de construção e reconstrução de conhecimentos a partir dos nossos sentidos em toda a plenitude, tomamos as narrativas escritas e analisamo-las tangenciado às categorias inspiradas nas relações significativas potencializadas pela sensível, sendo: Eu-Meio Ambiente, Eu- O Outro e Eu - Comigo Mesmo ${ }^{4}$.

Nesse sentido, com relação à categoria Eu- Meio ambiente destacamos os seguintes estratos:

Me senti, literalmente, na floresta! Foi bem legal perceber como somos muito mais dependentes do olfato do que costumamos achar. $(P 1)^{5}$

Fiquei extremamente tocada, mas tanto que senti vontade de chorar... me senti conectada com a terra, a “natureza” que ao mesmo tempo fora é inseparável de nós. (P2)

As narrativas acima expressam o que Matarezi (2006) denomina de "grande floresta”. A grande floresta é a metáfora da educação ambiental que comporta as características da natureza articuladas aos conhecimentos que iluminam e revelam os sentidos de um aprendizado crítico e emancipador. Ademais, os trechos citados revelam sensações antes não vivenciadas pelos participantes, o despertar da sua relação com o ambiente. Nesse sentido, a “Trilha dos Sentidos” está em consonância com um dos objetivos fundamentais da educação ambiental, onde de acordo com a Lei no 9.795/99, conhecida como Política Nacional de Educação Ambiental (PNEA), é necessária uma tentativa de promover uma visão mais holística do ambiente, preparando a todos os atores sociais envolvidos para participarem de maneira questionadora e ativa da sociedade.

Kondrat e Maciel (2013) revelam a importância de trabalhar-se em ambientes como florestas ou com conservação e preservação da diversidade biológica como, por exemplo, jardins botânicos e parques, pois favorece maior integração das pessoas ao meio ambiente (PIVELLI; KAWASAKI, 2005). Acreditamos que ao simular o ambiente de floresta, a Trilha dos sentidos também assume este papel.

As florestas reconstruídas a partir de materiais naturais constroem a relação da natureza com as Artes. Nesse trecho destacado, a fala dos participantes nos remete a evocação de imagens, assim como definida por Root-Bernstein (2001), pois como o autor destaca é importante a capacidade de recordar-se ou associar-se imagens aos sentimentos e emoções, mesmo sem vê-las, podendo ser criada por qualquer sentido. A evocação de imagens e estímulo à imaginação ocorreu durante todo o percurso da trilha, pois a todo tempo os participantes eram indagados sobre o que estavam sentindo ou se conseguiam decifrar o que estavam tocando ou cheirando.

4 Matarezi (2006).

5 Optamos por não identificar os sujeitos participantes. Utilizamos uma codificação de acordo com a ordem dos respondentes, onde o P refere-se ao participante. 
Os participantes também revelaram em suas narrativas, a relação Eu - Comigo Mesmo como uma forma de conhecer e (re) conhecer para, conforme destaca Matarezi (2006), (re) aprender a conviver, a transcender, me re-ligar com esta floresta.

Adorei trabalhar com os sentidos desta forma. Percebi que todos os sentidos (menos a visão) foram trabalhados mais de uma vez, alias vários ao mesmo tempo. Em muitos momentos foi necessário associar dois ou mais sentidos (cheirei , toquei).(P3)

Muito legal! Meu paladar foi praticamente anulado sem o olfato, bem interessante!(P2)

A partir destes relatos, podemos observar a percepção dos participantes quanto aos seus próprios sentidos, as suas observações no que se refere ao seu próprio corpo. Nesse sentido, destacamos a importância de se (re) conhecer para que, então, se possa entender sua posição no ambiente, refletindo como parte integrante deste. Como revela Bonoto, (2008) é necessário direcionarmos esforços no sentido de sua transformação. Isso implica em mudanças profundas em nossas concepções, valores e ações frente ao mundo, em nossos padrões de consumo e bem-estar e também em nossas relações sociedade-sociedade e sociedade-natureza.

Identificamos nas narrativas, evidências da relação $\mathrm{Eu}$ - O Outro, referindo-se às conexões que integram o sujeito ao lugar onde vive, como ressalta Matarezi (2006), incorporando as trajetórias pessoais e coletivas, os sonhos compartilhados e as utopias concretizáveis.

A oficina foi muito bem construída, permitindo que o participante interagisse e reconhecesse diferentes elementos associando com sua construção social de mundo e corpo. (P.5)

A experiência proporcionou várias sensações simples que não nos damos conta no nosso cotidiano. Nossos sentidos são esquecidos ou deixados de lado e são através deles que percebemos o mundo e as pessoas que nele habitam. A experiência de trabalhá-los de maneira focada nos permite valorizar e interagir melhor com o meio onde nos encontramos. (P6)

A experiência permitiu que fosse despertado a confiança e segurança no outro, pois estávamos com os olhos vendados e precisávamos a todo tempo sermos guiados. (P7).

Percebemos nos relatos que a vivência na trilha dos sentidos foi marcante, reforçando impressões de caráter subjetivo, relacionando a conscientização sobre necessidades próprias e reflexões sobre as responsabilidades individuais e coletivas. Matarezi (2006, p.194), explica que, “o objetivo primário não é somente aproximar as pessoas dos elementos naturais através dos sentidos, mas aproximar as pessoas delas mesmas, através do aprimoramento do autoconhecimento, e a partir daí reconstruir suas relações.”

Pode se perceber que em todos os relatos os participantes destacam a vivência de uma experiência sensorial e o desencadear de imagens sensoriais, como Root-Bernstein (2001) revela, essas atividades são ricas e complexas, sendo importantes de serem desenvolvidas em pessoas de todas as áreas, para que através da abstração possam se tornar mais criativas.

Ao analisar a atividade como um instrumento possível de ser trabalhado em ambiente escolar, todos os participantes relataram ser possível a sua aplicação devido a utilização de materiais acessíveis, porém destacaram como ponto que precisa ser analisado o tempo de duração da atividade, visto que, essa envolve a preparação do caminho a ser trilhado e a participação de apenas uma pessoa por vez. Com isso, concordamos com Guimarães (2013) ao revelar que "A educação ambiental deve ser um processo contínuo e permanente, iniciando em nível pré-escolar e estendendo-se por todas as etapas da educação formal ou informal” e atribuímos a "Trilha dos 
sentidos” um instrumento potencial para que a educação ambiental seja então trabalhada com alunos, visto que, sua apresentação aos estudantes seja relevante, significativa e apoiada pela prática (LEGAN, 2009).

O interesse na atividade foi demonstrado por todos os participantes, como pode ser visto em algumas frases abaixo, transcritas do questionário.

Minha percepção do trabalho foi a melhor possível. (P1)

A experiência foi bastante interessante. (P6)

Adorei a criatividade da experiência (P3)

Senti sensação de segurança, a vontade, prazerosa. (P4)

Esse dado é relevante, pois a "Trilha dos sentidos” é vista pela maioria dos participantes com interesse, podendo ser utilizada para atingir determinados objetivos pedagógicos, sendo uma alternativa para trabalhar questões que envolvem o Eu-Outro-Ambiente. Notoriamente, as atividades lúdicas, com o envolvimento das artes, são reconhecidas pela sociedade como meio de fornecer ao indivíduo um ambiente agradável, motivador, prazeroso, planejado e enriquecido, que possibilita a aprendizagem de várias habilidades (PEDROSO, 2009).

\section{APONTANDO SENTIDOS A PARTIR DOS CAMINHOS TRILHADOS}

Retomando nosso intuito de identificar as oportunidades de aprendizagens efetuadas por meio do corpo, dos sentidos e da percepção que articulasse o si mesmo, os outros e a natureza através da vivência na trilha dos sentidos, sinalizamos que a presente atividade possibilitou a experimentação de situações práticas que estimularam os sentidos e a imaginação, sendo atravessado pela responsabilidade individual e coletiva referenciadas à relação Eu-Meio-Ambiente.

Entendemos que nesse processo vivencial, os participantes puderam experimentar o entrelaçamento da sensibilização e conscientização, com vistas à tomada de decisões adequadas em sua vida diária, levando a cada um sentir-se parte da natureza. Consideramos que a atividade privilegia expressões consideradas artísticas, aliando o prazer, a surpresa e a alegria aos conteúdos instrucionais das Ciências, com maior enfoque na Educação Ambiental, ultrapassando em muito a dimensão de atividade apenas de sensibilização.

Há fortes razões para considerarmos o diálogo entre Ciência e Arte como uma espécie de didática no ensino, que poderia, com padrões mínimos de regularidade, motivar a criatividade e aumentar as possibilidades de êxitos nos processos de aprendizagem (FIGUEIRA-OLIVEIRA, 2009).

\section{COLABORADORES}

Todos os autores participaram igualmente do planejamento do estudo, da coleta de dados em campo, da discussão e da redação do texto do artigo. 


\section{REFERÊNCIAS}

AB'SABER, AZIZ NACIB. (Re)conceituando educação ambiental. In: Magalhães, Luiz Edmundo. A questão ambiental. São Paulo: Terra Graph, 1994.

BONOTTO, D. M. Educação ambiental e educação em valores em um programa de formação docente. Revista Electrónica de Enseñanza de las Ciencias, vol. 7, n.2, 2008, p. 313-336.

BRASIL. Secretaria de Educação Fundamental. Parâmetros Curriculares Nacionais: Ciências Naturais / Secretaria de Educação Fundamental. - Brasília: MEC/SEF, 1997 a.

CARVALHO, A.M.P.. A pesquisa em sala de aula e a formação de professores. In: A pesquisa em ensino de ciências no Brasil: alguns recortes. São Paulo: Escrituras Editora, 2007, p.193-218.

CARVALHO, A.M. P E GONÇALVES, M.E.R. Formação continuada de Professores: o vídeo como tecnologia facilitadora da reflexão. Cadernos de Pesquisa da Fundação Carlos Chagas, São Paulo, v.111, p.71-78, 2000.

FIGUEIRA-OLIVEIRA, D. Ciência e arte: um “entre-lugar” no ensino de Biociências e saúde, In: VII Encontro Nacional de Pesquisa em Educação em Ciências. Florianópolis, 2009.

FONTOURA H. A. Tematização como proposta de análise de dados na pesquisa qualitativa. In: FONTOURA, H. A (Org.) Formação de professores e diversidades culturais: múltiplos olhares em pesquisa. Niterói: Intertexto, 2011.

FREIRE, P. Pedagogia da Autonomia: saberes necessários à prática educativa. Editora Paz e Terra, São Paulo,1996. p. 122-126.

GUIMARÃES, M. Educação Ambiental Crítica. In: LAYRARGUES, P. P. (Coord.). Identidades da Educação Ambiental Brasileira. Brasília: Ministério do Meio Ambiente, Edições MMA, p.25-34, 2004.

Educação ambiental: participação para além dos muros da escola. In: Vamos cuidar do Brasil: conceitos e práticas em educação ambiental na escola. Brasília: Ministério da Educação, Ministério do Meio Ambiente, Departamento de Educação Ambiental: UNESCO, 2007.

A dimensão ambiental na educação. 11. ed. São Paulo: Papirus, 2013. KONDRAT, H; MACIEL, M. D. Educação ambiental para a escola básica: contribuições para o desenvolvimento. Revista Brasileira de Educação, v. 18, n. 55, 2013.

LEGAN, L. Criando habitats na escola sustentável: livro de Educador / Lucia Legan. - Imprensa Oficial do Estado de São Paulo, Pirenópolis, GO : Ecocentro IPEC, 2009.

LOUREIRO, C. F. B. Trajetória e fundamentos da educação ambiental. São Paulo: Cortez, 2005.

LÜDKE, M. e ANDRÉ, M. Pesquisa em educação: abordagens qualitativas. São Paulo: EPU, 1986. p.45-57.

MACHADO, M.A.S, et. al. Integralidade, formação de saúde, educação em saúde e as propostas do SUS: uma revisão conceitual. Cien Saude Colet; v.12, n.2, p.335-42, 2007.

MACIEL E.L.N, et. al. Projeto Aprendendo Saúde na Escola: a experiência de repercussões positivas na qualidade de vida e determinantes da saúde de membros de uma comunidade escolar em Vitória, Espírito Santo. Ciênc Saúde Colet. p. 389-96, 2010.

MATAREZI, J. Trilha da vida: (re)descobrindo a natureza com os sentidos. Ambiente \& Educação - Revista de Educação Ambiental da FURG, Rio Grande (RS): Fundação Universidade do Rio Grande, v. 5/6, p. 55-67, 2001. 
. Despertando os sentidos da educação ambiental. Educar, Curitiba, n. 27, p. 181-199, 2006.

MORIN, E. O homem e a morte. Rio de Janeiro: Imago, 1997.

PEDROSO, C. V. Jogos didáticos no ensino de biologia: Uma proposta metodológica baseada em módulo didático. IX Congresso Nacional de Educação- PUCPR, 2009.

PIVELLI, S. R. P; KAWASAKI, C. S. Análise do potencial pedagógico de espaços não formais de ensino para o desenvolvimento da temática da biodiversidade e sua conservação. In: V Encontro Nacional de Pesquisadores em Educação em Ciências, Bauru. Anais... Bauru: ABRAPEC, nov./dez. 2005.

ROOT-BERNSTEIN, R. e ROOT-BERNSTEIN, M. Centelha de gênios: como pensam as pessoas mais criativas do mundo/Robert e Michele Root-Bernstein. São Paulo: Nobel, 2001.

SANTOS, M.E.V.M. Desafios pedagógicos para o século XXI: suas raízes em forças de mudança de natureza científica, tecnológica e social. Lisboa: Livros Horizonte, 1999.

SOUZA, E. C. de. Memoriais autobiográficos, profissionalização docente e identidade: histórias de vida e formação na pós-graduação. In.:PASSEGGI, M.C.; BARBOSA, T.M. (Orgs.) Memórias, Memoriais: pesquisa e formação docente. Natal: EDUFRN; São Paulo: PAULUS, 2008, pp. 119/133.

TABANEZ, M. F. \& PADUA, S. M. 1997. Uma abordagem participativa para a conservação de áreas naturais: Educação ambiental na mata atlântica. Anais do Congresso Brasileiro de Unidades de conservação. Curitiba-Paraná, v. 2.

VERGNANO, S.S.. O meio ambiente a partir da Arte de Krajcberg: Perspectivas educacionais em Ciência e Arte. 2006 (Dissertação de Mestrado) do Programa de Pós-graduação em Ensino de Biociências e SaúdeInstituto Oswaldo Cruz-Fundação Oswaldo Cruz. Rio de Janeiro. 